\title{
Heart rate as a measure of stress in Antarctic krill, Euphausia superba
}

\author{
D.A. Ritz*J, L. Cromer*, K.M. Swadling*, S. Nicol ${ }^{\dagger}$ and J. Osborn ${ }^{\ddagger}$
}

\begin{abstract}
*School of Zoology, University of Tasmania, PO Box 252-5, GPO Hobart, Tasmania, 7001 Australia. ${ }^{\dagger}$ Australian Antarctic Division, Channel Hwy, Kingston, Tasmania, 7050 Australia. ${ }^{\ddagger}$ School of Geography and Environmental Studies, University of Tasmania,

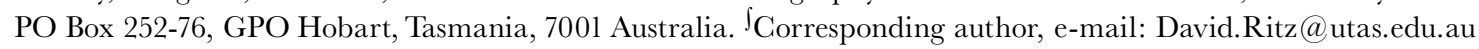

\begin{abstract}
Antarctic krill, Euphausia superba, normally live in social aggregations (schools) but rarely aggregate in laboratory tanks. In order to study the effect of stress on solitary living we tethered krill to wooden skewers and measured heart rate both when they were held isolated from conspecifics and when they were held at normal schooling distances ( 1 body length). Heart rate did not differ significantly with sex or body size. However, intermoult krill had a significantly lower heart rate than postmoult animals. When two individuals were held at schooling distance, with one slightly higher in the water column than the other, the heart rate of the higher individual slowed significantly (106-98 beats $\mathrm{min}^{-1}$ ), while that of the lower individual remained the same. We interpret these results to mean that krill living solitarily are stressed but will respond to neighbouring individuals by decreasing their metabolic rate and saving energy.
\end{abstract}

Only two authors have reported that Antarctic krill, Euphausia superba Dana, exhibited schooling behaviour when held in laboratory tanks (O’Brien, 1987; Strand \& Hamner, 1990). This is surprising given that krill in the field invariably occur in schools from furcilia stage IV (Hamner et al., 1989). We have tried without success to induce schooling in this species. Since we were unable to achieve this, we resorted to tethering krill so that they could be held in the configuration of a school in order that we could test the hypothesis that isolated individuals suffer stress which can be relieved when they gather in schools. Metabolic benefits of social aggregation have previously been demonstrated for mysids that save energy when in swarms (Ritz, 2000; Ritz et al., 2001). Live krill have been cultured at the Australian Antarctic Division in Kingston, Tasmania for over a decade but have never formed schools for more than very brief periods.

Individual krill were carefully blotted dry with tissue and the mid-dorsal region of the carapace was glued to the cut end of a wooden skewer with superglue. This usually took no more than $30 \mathrm{~s}$ after which they were rapidly immersed in water at $1^{\circ} \mathrm{C}$. In most cases krill began swimming movements immediately. The skewer was held firmly by pushing it through a sheet of polystyrene foam laid over the top of the glass tank (20-1). Recording of heart rate was by videofilming (Panasonic model WV BL600 fitted with a Nikon macro lens). The heart could be clearly seen through the transparent carapace and its beating was videofilmed for about $10 \mathrm{~min}$. Preliminary experiments showed that heart rate was elevated for a period after the tethering process but settled to a consistent rhythm after $30 \mathrm{~min}$ (elevated to active beating in the terminology of Cumberlidge \& Uglow, 1977). All subsequent recordings were made $30 \mathrm{~min}$ after tethering. Beating rates were later measured by replaying the tape through a monitor and counting beats for $30 \mathrm{~s}$ at a random interval through the record. After each experiment, the krill were sacrificed and carapace length, total length, moult stage and sex were noted. Experiments were conducted in a constant temperature room held at $3-4^{\circ} \mathrm{C}$, but seawater was stored in another room at $0-1^{\circ} \mathrm{C}$. The experimental tank was sheathed in polystyrene to maintain water temperature at $1^{\circ} \mathrm{C}$. Firstly two individuals were suspended in the tank at least
$15 \mathrm{~cm}$ apart, and their heart rates measured after the stabilization period. Then they were gently brought together by sliding the polystyrene along the top of the tank until they were the required distance apart. They were then allowed another stabilization period $(30 \mathrm{~min})$ before heart rates were again measured. Each experiment, i.e. single and paired krill, was replicated 12 times. We cannot compare heart rate of tethered and free swimming krill using our method, but the effect of tethering can be inferred from a comparison of pleopod beating in tethered and untethered krill. Our unpublished results for tethered animals after a $30 \mathrm{~min}$ recovery period were very close to Kils' (1981) results for free swimming krill (156 vs minimum of 144 beats $\min ^{-1}$, respectively).

Paired $t$-tests showed that there was no significant difference in heart rate of the lower of a pair of krill whether held singly or within one body length of a conspecific $\left(t_{11}=1.1 ; P>0.05\right)$. However, the heart rate of the upper of a pair of krill was significantly reduced compared to when it was held singly $\left(t_{11}=2.42\right.$; $P<0.05)$ (Figure 1).

Moult stage exerted a significant effect on heart rate. Intermoult krill had a lower rate than postmoult ones (104 vs 91.08 beats $\left.\min ^{-1} ; t_{22}=3.25, P<0.01\right)$. This is in accordance with Paranjape's (1967) results demonstrating that average respiration rate of Euphausia pacifica increased by about 34\% during moulting. However, differences in moult stage did not explain the significant reduction in heart rate of the upper of a pair of krill since these consisted of equal proportions of postmoult and intermoult individuals. We found no significant effect of body size or sex on heart rate. An inverse relationship with body size might be expected in adult crustaceans (Spicer \& Morritt, 1996). Actual rates agreed fairly closely with Schwartzkopff's (1955) data for animals of appropriate weight, though our rates were lower, which might be explained by the much lower temperature. Heart rate is considered to reflect metabolic rate (Depledge et al., 1996). We interpret our results to mean that krill respond to the presence of neighbours by lowering their metabolic rates and hence could save energy when in schools. Ritz (2000) found that mysids in swarms consumed much less energy than those in uncohesive small groups. He suggested that circulation patterns 


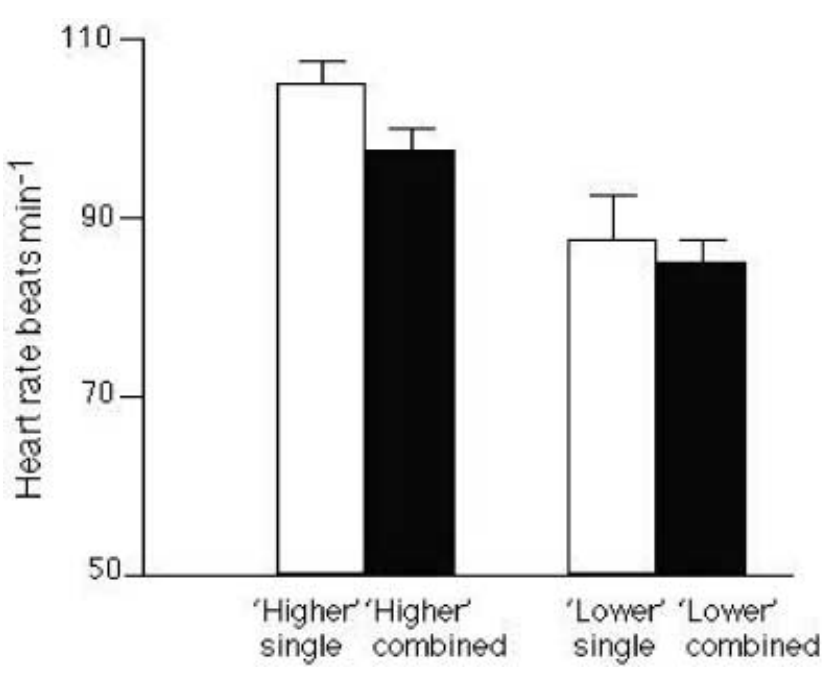

Figure 1. Heart rate (beats $\mathrm{min}^{-1}$ ) of Antarctic krill, Euphausia superba, held singly or in pairs.

generated by aggregations could result in updrafts that could be exploited by individuals to minimize their sinking rates. This could explain why the heart rate of the lower krill did not fall significantly. It is equally possible that when mysids form social groups this relieves the stress associated with solitary life and metabolic rate falls.

The heart rate of the higher group of krill was significantly faster than that of the lower group even when they were held singly. This could not be explained on the basis of a difference in distribution of moult stages between the two groups. It is possible that the difference was because the higher group were kept undisturbed in the water for a shorter period than the lower group before measurement and thus heart rate may have had less time to stabilize (even though both were allowed $30 \mathrm{~min}$ ). However, this could not explain the subsequent difference between higher and lower when tethered in pairs since both had been disturbed by adjusting their relative positions, and measurements were made at the same time interval after this disturbance.

The reduction in heart rate is small relative to the potential energy savings demonstrated for swarming mysids but if an individual krill was surrounded by neighbours as in a real school, the possibilities for stress-relieving stimuli or favourable currents would be much greater than in our experiment.
We are grateful to the Australian Research Council for funding this study.

\section{REFERENCES}

Cumberlidge, N. \& Uglow, R.F., 1977. Heart and scaphognathite activity in the shore crab, Carcinus maenas (L.). Fournal of Experimental Marine Biology and Ecology, 28, 87-107.

Depledge, M.H., Lundebye, A.-K., Curtis, T., Aagard, A. \& Andersen, B.B., 1996. Automated interpulse-duration assessment (AIDA): a new technique for detecting disturbances in cardiac activity in selected macroinvertebrates. Marine Biology, 126, 313-319.

Hamner, W.M., Hamner, P.P., Obst, B.S. \& Carleton, J.H., 1989. Field observations of the ontogeny of schooling of Euphausia superba furciliae and its relationship to ice in Antarctic waters. Limnology and Oceanography, 34, 451-456.

Kils, U., 1981. Swimming behaviour, swimming performance and energy balance of Antarctic krill, Euphausia superba. BIOMASS Scientific Series, 3, 1-233.

O'Brien, D.P., 1987. Direct observations of the behaviour of Euphausia superba and Euphausia crystallorophias (Crustacea: Euphausiacea) under pack ice during the Antarctic spring of 1985. Fournal of Crustacean Biology, 7, 437-448.

Paranjape, M.A., 1967. Molting and respiration of euphausiids. Fournal of the Fisheries Research Board of Canada, 24, 1229-1240.

Ritz, D.A., 2000. Is social aggregation in aquatic crustaceans a strategy to conserve energy? Canadian Fournal of Fisheries and Aquatic Sciences, 57, 59-67.

Ritz, D.A., Foster, E.G. \& Swadling, K.M., 2001. Benefits of swarming: mysids in larger swarms save energy. Fournal of the Marine Biological Association of the United Kingdom, 81, 543-544.

Schwartzkopff, J., 1955. Die grossenbhangig keit der herzfrequenz von krebsen im vergleich zur anderen tiergruppen. Experientia, 11, 323-325.

Spicer, J.I. \& Morritt, D., 1996. Ontogenetic changes in cardiac function in crustaceans. Comparative Biochemistry and Physiology, 114A, 81-89.

Strand, S.W. \& Hamner, W.M., 1990. Schooling behaviour of Antarctic krill (Euphausia superba) in laboratory aquaria: reactions to chemical and visual stimuli. Marine Biology, 106, $355-360$. 